\title{
Forecasting of traffic flows and their development in the implementation of the transport strategy in the Far North
}

\author{
Viktor Buneev ${ }^{1, *}$, Victoria Vinichenko ${ }^{1}$, Sergey Maslennikov ${ }^{1}$ \\ ${ }^{1}$ Siberian state University of water transport, Novosibirsk, Russia, Shchetinkina str., 33, 630099, \\ Novosibirsk, Russia
}

\begin{abstract}
The purpose of this study was to determine the role of public policy in creating a favorable environment for the development of the national economy and improve social and economic well-being through the creation of a safe and convenient transport structure. Special attention of the authors is drawn to the Decree of the government of the Russian Federation of 22.11.2008 No 1734-R "On the transport strategy of the Russian Federation". The purposeful value of the above mentioned by-law is considered. As an indicator of the quality of transport services "Transport strategy of Russia until 2030", it assumes a steady increase in transport mobility of the population of the Russian Federation, as well as the integration of the Russian transport system into the international one. The results of forecasting of some key indicators of the Transport strategy are presented. Since the implementation of the strategy was actually launched back in 2009, it is already possible to judge the achievement (or, more precisely, the lack of achievement) of the criteria considered. It was found that there was a close link between the quantity of goods carried and the quantity of goods overloaded the net financial result and some other indicators. Feedback was identified between the same trait under study and the wear and tear of fixed assets. Thus, knowing the factors that have a direct impact on the result, you can manage it. And the achievement (or non-achievement) of the target indicators becomes an elective parameter influencing firstly on the variant of the development scenario (basic or innovative), and secondly, on the social and economic situation of the studied region. The main task of the state in the sphere of functioning and development of transport system of Russia.
\end{abstract}

\section{Introduction}

Transport companies, being the most important part of the infrastructure of the national economy, always closely monitor the development and strategic decisions of the government apparatus. As a rule, strategic decisions aimed at the socio-economic development of the country include projects for the modernization of transport infrastructure. These are measures to develop Russia's export potential, including the development of seaports, improvement of the technical condition of the TRANSSiberian railway, inclusion in the transport system of the Northern sea route, as well as measures to

\footnotetext{
* Corresponding author: v.m.buneev@nsawt.ru
} 
improve competitiveness and transport accessibility. Significant resources are invested by the state in the construction of roads. Noticeable changes occurred on the railroad - cars, locomotives, means of automation and control were updated. These measures were included in Federal development programmes and received state support. Transport as a commercial structure started to be mentioned relatively recently. Because of this, transport workers still work with the hope for inter-budget transfers, not having time to integrate into the hypercompetitive imperative model of the world. The Government of the Russian Federation strives to narrow the gap in the backlog and pays serious attention to indicators of the quality of transport services. Criteria for its efficiency are indicated in the "Transport Strategy of the Russian Federation for the period until 2030" [4]. Among them are: speed, timeliness, predictability, rhythmicity, safety, environmental friendliness. The strategy provides for the availability of forecast indicators in the form of target indicators, which are calculated on the basis of an innovative and basic development of the country's transport system. Within the framework of the strategy, six main goals have been formulated. Their achievement, according to the plan of the Government of the Russian Federation, will lead to the formation of a single transport space of Russia, distinguished by safety, accessibility, quality of service and environmental friendliness. At the same time, it is assumed that such a system can easily integrate into the international space. A number of tasks are set for each goal, which contribute to their achievement. However, despite the attractiveness of the "Strategy", it has a number of problems that arose even before its development was completed in the modern form. Since the "Strategy" was adopted by the Decree of the Government of the Russian Federation No. 1734-R of 22.11.2008 "On the transport strategy of the Russian Federation", some of the projected values given in the text can already be checked.

\section{Methods of research}

Within the framework of the strategy, six main goals have been formulated. Their achievement, according to the plan of the Government of the Russian Federation, will lead to the formation of a single transport space of Russia, distinguished by safety, accessibility, quality of service and environmental friendliness. At the same time, it is assumed that such a system can easily integrate into the international space. A number of tasks are set for each goal, which contribute to their achievement [1].

However, despite the attractiveness of the "Strategy", it has a number of problems that arose even before its development was completed in the modern form. Since the "Strategy" was adopted by the Decree of the Government of the Russian Federation No. 1734-R of 22.11.2008 "On the transport strategy of the Russian Federation", some of the projected values given in the text can already be checked. For example, the authors calculated [2] that such a target indicator as the transport mobility of the population was not achieved already in 2015. This indicates the need to update the "Transport Strategy of the Russian Federation for the period until 2030" in connection with the risk factor and uncertainty, as well as significant changes that occurred at the macroeconomic level. One of the key parameters of transport services in accordance with social standards is the transport mobility of population. The "Strategy" predicted the values of indicators for innovative and basic development options (Table 1).

Table 1. The values of the indicator "Transport mobility of population, billion pass-km per 1 person per year by mode of transport" (Source: Transport Strategy of the Russian Federation until 2030 [4]).

\begin{tabular}{|l|l|l|l|l|l|l|l|}
\hline \multirow{2}{*}{$\begin{array}{l}\text { Development } \\
\text { option }\end{array}$} & \multicolumn{6}{|l|}{ Value of the indicator by years } \\
\cline { 2 - 8 } & 2010 & 2011 & 2015 & 2018 & 2020 & 2024 & 2030 \\
\hline Innovative & 6564 & 6916 & 8257 & 9596 & 10446 & 12252 & 15561 \\
\hline Basic & 6564 & 6916 & 7981 & 8931 & 9746 & 11039 & 13308 \\
\hline
\end{tabular}


For comparison, it is necessary to make a forecast by the method of linear extrapolation, for which we use the data of Table 2 .

Table 2. Values of indicators for calculating the mobility of population by years (Source: Russia in Figures. 2017: Krat.stat.SB./Rosstat - M., P76 2017-511 p. [5], [6]).

\begin{tabular}{|l|c|c|c|c|c|c|c|}
\hline \multirow{2}{*}{ Indicator } & \multicolumn{7}{|c|}{ Value of the indicator by years } \\
\cline { 2 - 9 } & 2010 & 2011 & 2015 & 2018 & 2020 & 2024 & 2030 \\
\hline $\begin{array}{l}\text { Number of passengers carried } \\
\text { by year, billion pass-km }\end{array}$ & 484 & 502,8 & 532,6 & 547,2 & 556,2 & 530 & 519,8 \\
\hline Population, billion people & 0,1429 & 0,1429 & 0,1433 & 0,1437 & 0,1463 & 0,1465 & 0,1468 \\
\hline $\begin{array}{l}\text { Mobility of population, billion } \\
\text { pass-km per 1 person per year }\end{array}$ & 3387 & 3519 & 3717 & 3808 & 3802 & 3618 & 3541 \\
\hline
\end{tabular}

Using the method of linear extrapolation, we will predict whether it is possible to achieve the projected values mentioned in the Strategy without realizing the tasks assigned to meet the goals (Table 3).

Table 3. Calculation of the growth rate of transport mobility of population by years (Source: Compiled by the author according to Table 2).

\begin{tabular}{|c|c|c|}
\hline Year & $\begin{array}{c}\text { Mobility of population, pass-km per 1 } \\
\text { person per year }\end{array}$ & Growth rate, pass-km per 1 person per year \\
\hline 2010 & 3387 & - \\
\hline 2011 & 3519 & 131,56 \\
\hline 2012 & 3717 & 198,13 \\
\hline 2013 & 3808 & 91,25 \\
\hline 2014 & 3802 & $-6,16$ \\
\hline 2015 & 3618 & $-184,03$ \\
\hline 2016 & 3541 & $-76,88$ \\
\hline
\end{tabular}

Based on Table 2, we calculate the average growth rate per year. It will be 25.65 billion pass-km per person per year. The estimated value of transport mobility in 2030 is only 3900 instead of 15561 in the innovative scenario and 13308 in the basic scenario. The difference is more than 3 times. Since the strategy was approved in 2008, even 2015 was forecasted at the time of approval. It is already clear that this indicator in 2015 did not reach the planned value. In 2014 there was a sharp weakening of the national currency rate and also destabilization of foreign policy space. Such circumstances entailed unforeseen results and the risks of their occurrence were not included in the strategy. If other equal conditions remain unchanged, such a key indicator as "the volume of cargo transported to the regions of the Far North and equivalent areas" with the use of river transport will not be achieved even in the basic scenario, and in maritime transport this indicator will tend to absolute zero. To monitor the achievement of the second target "Ensuring the accessibility, volume and competitiveness of transport services according to the quality criteria for cargo owners at the level of the needs of innovative development of the economy of the country", the following target indicators are provided:

- the volume of traffic along the Northern Sea Route (NSR), million tons (Table 1);

- the volume of cargo transported to the regions of the Far North and equivalent areas, million tons (Table 4).

However, it must be remembered that the presence of correlation dependence does not always confirm the cause and effect relationship and may be a consequence of some other reason not included in the study. In this regard, the study of the causes that affect the target indicators should be more profound, and the selection of factor attributes should be more scientifically reasoned. The obtained data will simplify the processes of strategic and operational planning at water transport enterprises. Fundamental condition for reducing the impact of negative factors on the system of northern deliveries will be a set of state 
regulators that determine the level of macroeconomic activity of the state, among which can be named:

- state order;

- state credits and loans;

- tax incentives;

- state subsidies and transfers;

- state ownership of movable and immovable property involved in the implementation of northern deliveries.

The key long-term reference points for the formation of state regulators should be:

1) Targeting on the impact of the state apparatus on factors that adversely affect the organization of northern deliveries. It will be not only a guarantor of security for participants in the transportation process, but will also increase the level of confidence in the Government of the inhabitants of the northern regions.

2) State programming, which proposes the development and implementation of interrelated goals, time frames and resources of measures aimed at supporting indigenous and small-numbered peoples of the Far North, as well as the organization of uninterrupted delivery of vital goods to the permanent frost regions.

3) Planning and forecasting, which must necessarily be periodically updated taking into account the current market and macroeconomic situation (in some cases, climate).

\section{Results}

The result of the study was the forecast indicators of the mastering of cargo flows to the regions the Far North and equivalent areas in 2030, mastered by river and sea modes of transport. The need to update the "Transport strategy of the Russian Federation for the period until 2030" is identified in connection with the risk factor and uncertainty, as well as significant changes that occurred at the macroeconomic level. In 2014 there was a sharp weakening of the national currency rate, and also destabilization of foreign policy space. Perhaps, this was one of the reasons for the decrease in volume of turnover in the territories under consideration. However, with a more detailed examination, it becomes noticeable that the fall in values began back in 2011. This only confirms the need for a thorough study of the reasons for not reaching the forecast values. If other equal conditions remain unchanged, such a key indicator as "the volume of cargo transported to the regions of the Far North and equivalent areas" with the use of river transport will not be achieved even in the basic scenario, and in maritime transport this indicator will tend to absolute zero.

In addition to the impact of external factors, the volume of financing is a subject to revision. One cannot ignore the galloping pace of introducing innovations. In this regard, the need to take into account the Strategy for the Innovative Development of the Russian Federation for the period until 2020, the Strategy for the Development of the Arctic Zone of the Russian Federation and National Security for the period until 2020, the Strategy for the Development of the Shipbuilding Industry for the period until 2020 and for the future, the Strategy for the Development of Transport Engineering in the Russian Federation in 20072010 and for the period until 2015, the Strategy for the Development of Aviation Industry for the period until 2015, the Strategy for the development of Automotive Industry of the Russian Federation for the period until 2020, and other industrial strategies in the sphere of industry, energy, forestry and agriculture, the strategy of social and economic development of Russian regions is identified.

\section{Discussion}


The reasons for not reaching the target indicators are the subject to thorough study and analysis. That was done in the authors' research. It was established that there is a close direct connection between the amount of cargo transported and the amount of the overloaded cargo, the balanced financial result and some other indicators. Feedback was revealed between the same investigated feature and depreciation of fixed assets. Therefore, knowing the factors that have a direct effect on the result, you can manage the result. And the achievement (or non-achievement) of target indicators becomes an elective parameter influencing firstly on the variant of the development scenario (basic or innovative), and secondly, on the social and economic situation of the studied region. It's been a long time since it's not the news that "... traffic growth stimulates an increase in investment activity ..." [3]. That positively affects not only the welfare of population, but also the opportunities for the development of small and medium-sized businesses with its inherent synergetic effect. However, it must be remembered that the presence of correlation dependence does not always confirm the cause and effect relationship and may be a consequence of some other reason not included in the study. In this regard, the study of the causes that affect the target indicators should be more profound, and the selection of factor attributes should be more scientifically reasoned.

\section{Conclusion}

Today, transport companies stand on its own feet, carry out reorganization procedures, buy and sell fixed assets, and build investment policy. The best companies have mastered the harsh experience of forming sustainable transport and logistics relationships with consignees, have acquired the practice of creating reliable supply chains of material and technical resources, have become sophisticated financiers in conditions of acute seasonal shortage of money, and have mastered the maneuvering skill of manpower. The development of companies is due to internal reserves.

But the important thing in the new state policy is that an opportunity remains both for state participation in individual projects and for the participation of transport enterprises in solving social and economic projects. Usually, such projects are financed within the industry and have state subsidies. The creation of a state system of standards for transport services, as well as adaptation of existing parameters, will contribute to the development of an enabling environment for the formation of an investment climate, which is extremely important not so much in terms of increasing the economic welfare of the region, but rather from the perspective of overcoming transport discrimination of isolated territories, which are still a lot in Russia. In addition, it is planned to finance the modernization of the educational and laboratory base of universities engaged in training specialists in the field of industry and to carry out applied scientific research. It is advisable to carry out this work jointly by transport companies, universities in the field of transport, and also budgets of various levels.

\section{References}

1. V.M. Buneev, V.A. Vinnichenko, Vestnik NGIEI 4(63), 115-123 (2018)

2. V.A. Vinichenko, Theory and practice of public service, 12 (2017)

3. Yu.G. Tyurina, Siberian financial school 5, 3-8 (2017)

4. Transport strategy of the Russian Federation for the period until 2030

5. Russia in numbers (Krat.stat.SB./Rosstat, Moscow, 2017)

6. Transport and communications in Russia (Stat.SB./Rosstat, Moscow, 2016) 